\title{
Ausschreibung für die Auszeichnung „Bibliothek des Jahres 2020“ - Innovationen für die digitale Welt sowie für die Auszeichnung „Bibliothek des Jahres in kleinen Kommunen und Regionen“
}

https://doi.org/10.1515/bd-2020-0030

Der Deutsche Bibliotheksverband e.V. (dbv) und die Deutsche Telekom Stiftung verleihen am 24. Oktober 2020 - dem „Tag der Bibliotheken“ - zum 21. Mal den Preis „Bibliothek des Jahres“ am Ort des Preisträgers. Die Auszeichnung „Bibliothek des Jahres“ ist der einzige nationale Bibliothekspreis in Deutschland. In 2020 wird erstmals auch die Auszeichnung „Bibliothek des Jahres in kleinen Kommunen und Regionen“ verliehen.

- Mit der Auszeichnung „Bibliothek des Jahres“ soll ein Beitrag zum Image der Bibliotheken in der digitalen Welt geleistet werden.

- Die Auszeichnung würdigt Bibliotheken aller Sparten und Größen.

- Ausgezeichnet wird vorbildliche und innovative Bibliotheksarbeit unter Nutzung von digitalen Angeboten und Services, auch in Teilbereichen ${ }^{1}$.

- Die Auszeichnung soll Motivation der Bibliotheken im Wettbewerb um Qualität und Innovation sein.

- Der Preis ist mit 20.000 Euro dotiert.

- Vorschlagsberechtigt sind die Sektionen, Landesverbände und Kommissionen des dbv sowie die Jurymitglieder. Eine Eigenbewerbung ist ebenfalls möglich. Bewerbungen können wiederholt eingereicht werden.

Für die Auszeichnung der Bibliothek sind maßgebend:

- die Qualität und Innovation der bibliothekarischen Arbeit,

- die Darstellung ihrer Konzeption oder Strategie,

- ihr kreativer Einsatz von digitalen Möglichkeiten,

- ihre Zukunftsorientierung,

- ihre nachhaltige Wirkung,

- ihre attraktiven Serviceleistungen,

1 Gemeint sind besonders vorbildliche und innovative Teilbereiche einer Bibliothek (z. B. Zweigstelle, Abteilung, Veranstaltungsarbeit, Bibliothek und Bildung, Integration, Informationskompetenz u.a.). 
- ihre medienwirksame Öffentlichkeitsarbeit,

- ihr überregionales/internationales Engagement,

- ihre (lokale, regionale, internationale) Vernetzung,

- die Qualität der Bewerbungsunterlagen.

\section{Der Preisträger wird von einer unabhängigen Jury gewählt.}

Sie besteht aus folgenden stimmberechtigten Mitgliedern:

- einem Vertreter der Bundesregierung,

- einem Vertreter der Kultusministerkonferenz,

- einem Vertreter des Deutschen Städtetages,

- einem Vertreter der Deutsche Telekom Stiftung,

- einem Vertreter des Dachverbandes Bibliothek \& Information Deutschland (BID),

- dem Präsidenten / der Präsidentin des Deutschen Bibliotheksverbandes e.V. (dbv) sowie

- zwei Mitgliedern des Bundesvorstandes des Deutschen Bibliotheksverbandes e.V. (dbv).

Die Jury, der bis zu zwei weitere Mitglieder ohne Stimmrecht angehören können, trifft ihre Entscheidung über die beim dbv eingereichten Vorschläge auf der Grundlage von Bewerbungen und nach Möglichkeit von Ortsbesichtigungen. Mitglieder des Bundesvorstandes und des Präsidiums des Bibliotheksverbandes können bei der Preisvergabe nicht berücksichtigt werden. Bewerbungen sind erst in dem Jahr möglich, das der aktiven Vorstands- oder Präsidiumstätigkeit folgt.

Die Preisverleihung erfolgt am Ort der ausgezeichneten „Bibliothek des Jahres“.

Erstmals wird auch die Auszeichnung „Bibliothek des Jahres in kleinen Kommunen und Regionen" für vorbildliche und innovative Bereiche einer Bibliothek verliehen.

- Mit der Auszeichnung „Bibliothek des Jahres in kleinen Kommunen und Regionen"soll ein Beitrag zum Image der Bibliotheken in den kleinen Kommunen und Regionen geleistet werden.

- Die Auszeichnung würdigt Bibliotheken aller Sparten in Städten und Gemeinden mit bis zu 50.000 Einwohnern.

- Ausgezeichnet wird vorbildliche und innovative Bibliotheksarbeit auch in Teilbereichen (z. B. Veranstaltungsarbeit, Bibliothek und Bildung, Integration, Informationskompetenz u. a.)

- Die Auszeichnung soll Motivation der Bibliotheken im Wettbewerb um Qualität und Innovation sein.

- Der Preis ist mit 7.000 Euro dotiert. 
- Vorschlagsberechtigt sind die Sektionen, Landesverbände und Kommissionen des dbv sowie die Jurymitglieder. Eine Eigenbewerbung ist ebenfalls möglich. Bewerbungen können wiederholt eingereicht werden.

- Eine Bewerbung kann nur einmal in einer der beiden Kategorien „Bibliothek des Jahres“ oder „Bibliothek des Jahres in kleinen Kommunen und Regionen“ eingereicht werden. Doppelbewerbungen sind nicht zulässig. Die Jury behält sich bei entsprechender Eignung vor, die Kategorie der Bewerbung zu ändern.

\section{Wichtige Termine:}

Einreichung von Vorschlägen bis zum $\quad 31.03 .2020$

Preisverleihung am

24.10.2020

Die Vorschlagsberechtigten für die Auszeichnung „Bibliothek des Jahres“ - entweder die Bibliotheksleitungen selbst, die Vorsitzenden der Sektionen, Landesverbände und Kommissionen des dbv oder die Jurymitglieder - füllen bitte ausschließlich den elektronischen Bewerbungsbogen aus, der auf der Website des dbv unter folgendem Link zu finden ist: http://www.bibliotheksverband.de/ dbv/auszeichnungen/bibliothek-des-jahres/bewerbung.html. Zusätzliche Dokumente können dort mit hochgeladen werden.

Die Vorschlagsberechtigten für die Auszeichnung „Hervorragende Bibliothek in kleinen Kommunen und Regionen“- entweder die Bibliotheksleitungen selbst, die Vorsitzenden der Sektionen, Landesverbände und Kommissionen des dbv oder die Jurymitglieder - füllen bitte ausschließlich den elektronischen Bewerbungsbogen „Bibliothek des Jahres in kleinen Kommunen und Regionen“ aus, der auf der Website des dbv unter folgendem Link zu finden ist: http://www. bibliotheksverband.de/dbv/auszeichnungen/bibliothek-im-ländlichen Raum/ bewerbung.html. Zusätzliche Dokumente können dort mit hochgeladen werden.

\section{Für Rückfragen wenden Sie sich bitte an:}

Barbara Schleihagen

Bundesgeschäftsführerin

Tel.: 030 / 644989910

E-Mail:dbv@bibliotheksverband.de

URL: www.bibliotheksverband.de 